This is the final accepted manuscript of:

\title{
Lanthanoid tetrazole coordination complexes
}

Mark I. Ogden, Massimiliano Massi, Stefano Stagni, Coordination Chemistry Reviews 2018, 375,(15), $164-172$

DOI: $10.1016 /$ j.ccr.2017.11.017

Publication Date (Web): December 7, 2017

Available

https://www.sciencedirect.com/science/article/pii/S0010854517305490?via\%3Dihub

Copyright @ 2017 Elsevier B.V: 


\section{Lanthanoid Tetrazole Coordination Complexes}

Massimiliano Massi, ${ }^{a}$ Stefano Stagni, ${ }^{b}$ and Mark I. Ogden $*^{a}$

${ }^{a}$ Department of Chemistry and Curtin Institute for Functional Molecules and Interfaces, Curtin University, Kent Street, Bentley 6102, WA, Australia. E-mail: m.ogden@curtin.edu.au

${ }^{b}$ Department of Industrial Chemistry “Toso Montanari’, University of Bologna, Viale Risorgimento 4, 40129 Bologna, Italy.

\section{Contents}

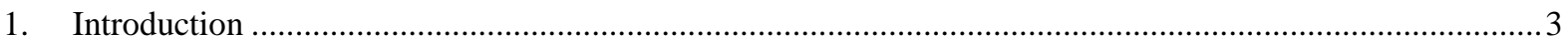

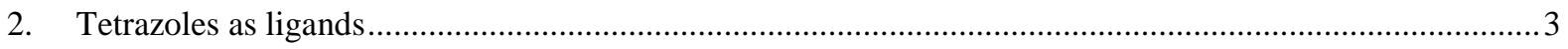

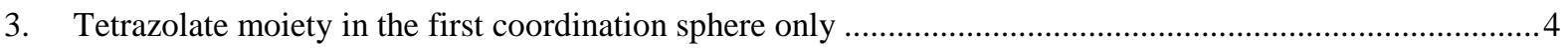

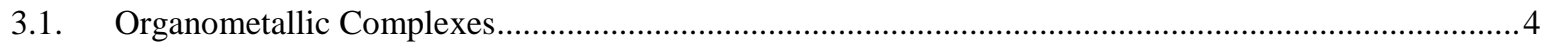

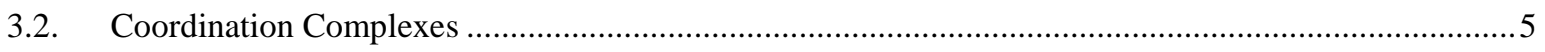

4. Tetrazolate moiety bridging metal atoms from the first to the second coordination sphere .......................

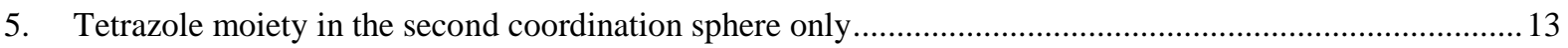

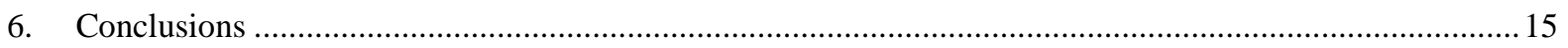

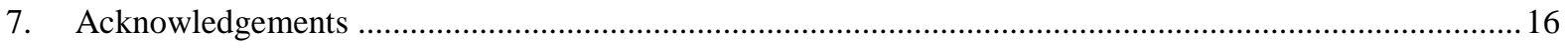

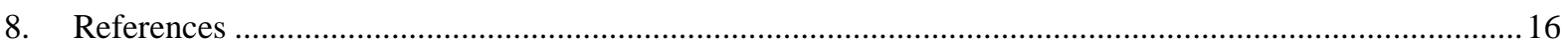




\begin{abstract}
While tetrazole derivatives are well established as anionic ligands for d-block elements, there is a growing interest in lanthanoid complexes of these compounds. Diverse structural chemistry results from the presence of four potential donor $\mathrm{N}$ atoms, and the conjugated nature of the heterocycle can impact on the photophysical properties of the complexes. This review examines the range of structurally characterised lanthanoid-tetrazolato complexes, focussing on the structural features of the ligand that impact on the tendency to interact with the first or second coordination spheres.
\end{abstract}

\title{
Keywords
}

Lanthanoid; tetrazole

\section{Introduction}

Tetrazoles are well established ligands for the d-block elements, with an extensive range of structurally characterised complexes reported.[1,2] Given the tendency of lanthanoid cations to bind to oxygen donor ligands in preference to softer nitrogen donors, it is not surprising that there is an order of magnitude less structurally characterised examples of lanthanoid tetrazolato complexes. While often described as an isostere for the carboxylate groups,[3] the tetrazolate anion is an aromatic heterocycle with four potential donor atoms imparting diverse structural chemistry. Tetrazoles can also be used in conjugation with other aromatic moieties as ligands to activate sensitisation of lanthanoid luminescence via the antenna effect.[4]

Here, our focus is on the structure of lanthanoid complexes bound to, or interacting with, tetrazolate anions, including the impact of the heterocycle as a hydrogen bond acceptor. The affinity of lanthanoids for O-donor ligands, and particularly water, combined with the hydrogen bond acceptor capacity of tetrazole-based ligands, is likely to favour tetrazoles being found in the second coordination sphere of the lanthanoids, all other factors being equal. This review examines structurally characterised lanthanoid-tetrazolato complexes from this perspective, with the aim of gaining an overview of how tetrazolato ligands interact with the first and second coordination spheres of lanthanoid cations.

\section{Tetrazoles as ligands}

The tetrazole ring comprises an aromatic heterocycle formed by four $\mathrm{N}$ atoms and one $\mathrm{C}$ atom. In its neutral form, the tetrazole functionality possesses an acidic NH bond whose $\mathrm{p} K_{\mathrm{a}}$ is similar to those of carboxylic acids $(\approx 5)$. The $\mathrm{H}$ atom is connected to either the $\mathrm{N} 1$ or $\mathrm{N} 2$ atoms of the tetrazole ring with the tautomers being in equilibrium (Scheme 1).[5] The similar $\mathrm{p} K_{\mathrm{a}}$ makes tetrazoles and carboxylic acids analogous functional groups in many aspects of molecular design. In fact, in medicinal chemistry it is not uncommon to consider tetrazoles as the more metabolically stable version of carboxylic acids.[3, 6, 7] Upon deprotonation, tetrazoles become negatively charged $\mathrm{N}$-donor ligands characterised by the presence of four lone pairs on the $\mathrm{N}$ atoms that are able to engage in bonding with metal centres, with the negative charge delocalised across the heterocyclic ring. The 
presence of these lone pairs oriented towards different directions in space is the origin of the versatility of the tetrazolate anion in forming a multitude of coordination complexes ranging from mononuclear species to molecularly defined coordination clusters, coordination polymers, and coordination frameworks.[1, 8] While coordination of the tetrazole ring to metal centres can occur via the aromatic $\pi$ electrons, these interactions are very rare with respect to the coordination of metal centres through the lone pairs on the $\mathrm{N}$ atoms.

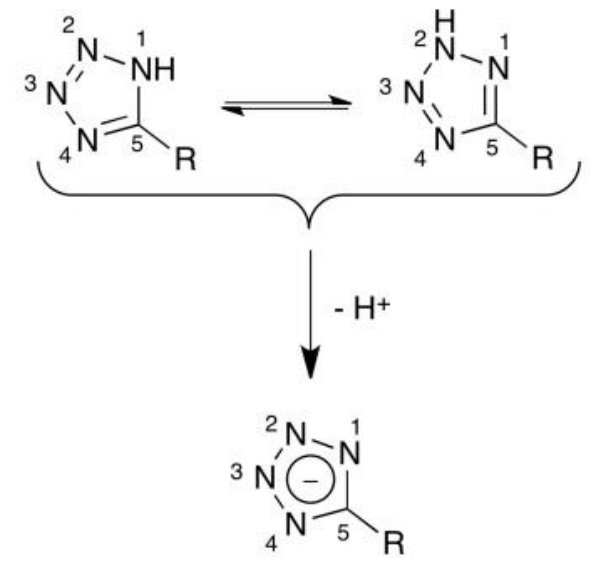

Scheme $1.1 H$ - and $2 H$ - tautomers of 5-substituted tetrazoles, and the deprotonation reaction.

The synthetic strategies for the preparation of tetrazole-containing molecules typically rely upon the 1,3-dipolar cycloaddition reaction between a nitrile precursor and an azide anion source.[5, 7, 9, 10] This well established procedure has been the object of intense investigation,[11-14] and there is still an open debate as to whether, from a mechanistic point of view, the ring closure reaction occurs in a concerted or multi-step fashion.[15] The tetrazole heterocycle can be irreversibly alkylated at N1 or N2, effectively becoming a neutral ligand. This substantially changes the nature of the resulting compounds as ligands, particularly with respect to lanthanoid coordination chemistry, as will be discussed below.

When considering the coordination chemistry of tetrazolate anions and f-block elements, searching the Cambridge Structural Database for structures incorporating a lanthanoid and a tetrazole moiety results in $\sim 240$ hits (as of September 2017), with over one third of these structures reported since 2015. The ligands range from polydentate systems designed to chelate lanthanoid cations, to unidentate tetrazole-containing molecules, as well as many that incorporate a number of different functional groups. Rather than discuss the lanthanoid complexes of these ligands classed by ligand type, the complexes have been grouped in the following sections according to which coordination sphere the tetrazole moieties are found to reside in, with an emphasis on bridging between metal ions. We discuss first the systems where the tetrazole ligands are found in the first coordination sphere (bound directly to the metal ion), and then move on to the extensive examples where second sphere interactions are observed, typically through hydrogen bonds linking the tetrazole moieties to the ligands bound directly to the metal.[16]

\section{Tetrazolate moiety in the first coordination sphere only}

\subsection{Organometallic Complexes}

A small number of tetrazole-containing organometallic lanthanoid complexes have been structurally characterised.[17, 18] The ligands that have been used in such complexes are shown in Figure 1. All these 
systems include cyclopentadienyl co-ligands, and have $\eta^{2}$-tetrazolate interactions. The complex of the formally neutral 1 is monometallic $\left(\mathrm{C}_{5} \mathrm{Me}_{5}\right)_{2} \mathrm{Sm}_{\mathrm{I}}(\mathbf{1})$,[17] while the reported complexes of anionic $\mathbf{2}$ are dinuclear, bridged by two $\mu-\eta^{1}: \eta^{2}$-tetrazolate moieties. One of the reported complexes is formulated as $\left[\left(\mathrm{C}_{5} \mathrm{H}_{4} \mathrm{Me}\right)_{2} \mathrm{Yb}\left(\mu-\eta^{1}: \eta^{2}-(2-\right.\right.$ $\mathrm{H})]_{2}$ (Figure 1). [18] The others contain mixed cyclopentadienyl ligands, reported to result from cyclopentadiene impurities in methylcyclopentadiene. The resulting complexes were formulated as $\left[\left\{\left(\mathrm{C}_{5} \mathrm{H}_{4} \mathrm{Me}\right)\left(\mathrm{C}_{5} \mathrm{H}_{5}\right) \operatorname{Ln}\left(\mu-\eta^{1}: \eta^{2}-(2-\mathrm{H})\right)\right\}_{2}\right]\left[\left\{\left(\mathrm{C}_{5} \mathrm{H}_{4} \mathrm{Me}\right)_{2} \operatorname{Ln}\left(\mu-\eta^{1}: \eta^{2}-(2-\mathrm{H})\right)\right\}_{2}\right], \mathrm{Ln}=\mathrm{Gd}$, Dy. In all cases the coordination mode of the tetrazole ligand was consistent.[18] In these systems, the tetrazole derivative ligands do not compete with any O-donor ligands, and hence are expected to be found in the first coordination sphere.

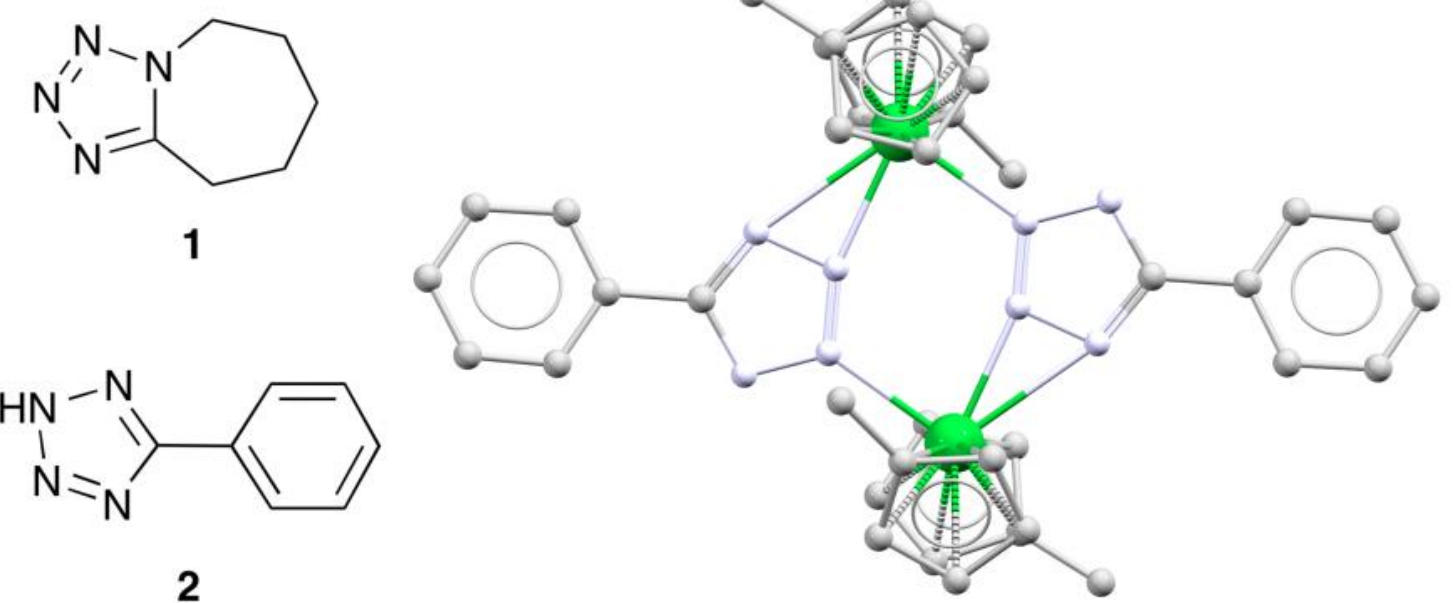

Figure 1. Tetrazole ligands used in structurally characterised organometallic lanthanoid complexes:

1,[17] 2, and a representation of the molecular structure of $\left[\left(\mathrm{C}_{5} \mathrm{H}_{4} \mathrm{Me}\right)_{2} \mathrm{Yb}\left(\mu-\eta^{1}: \eta^{2}-(2-\mathrm{H})\right)\right]_{2}$ emphasising the tetrazole ligand bridging mode.[18]

\subsection{Coordination Complexes}

There are relatively few lanthanoid-tetrazolate complexes that do not involve tetrazole groups interacting with the second coordination sphere of the lanthanoid cation. In all but one case, such complexes involve ligands with high denticity, at least tridentate (Figure 2). These complexes have been predominantly investigated for their luminescent properties deriving from the specific lanthanoid cation. The strategy of attaching the tetrazole functionality into a high denticity ligand structure is aimed at preventing water molecules to be directly bound in the first coordination sphere of the lanthanoid centres. In fact, it is well known that high frequency $\mathrm{OH}$ vibrational modes quench the lanthanoid excited states via multiphonon relaxation.[4] Aside from this structural functionality, many of the ligands reported in Figure 2 act as sensitisers for the lanthanoid luminescence through the antenna effect to overcome the inefficient direct excitation of f-f transitions.[4] In this respect, while tetrazoles and carboxylic acids might act in an analogous fashion from a structural point of view, the extended conjugation offered from the tetrazole moiety offers further versatility in tuning the energy of the excited states of the ligand in order to optimise the antenna effect.[19-21] Such a function is generally enhanced by direct coordination of the ligand to the metal ion, hence incorporating tetrazoles as the binding site for antenna ligands is generally associated with the use of multidentate ligand structures. The ready functionalisation of ligands (such as changes in the "R" group of 7) has been exploited to control properties such as solubility, and to provide functionalisation for connectivity, while maintaining consistent photophysical properties.[21] 
<smiles>[R]c1cc(-c2cccc(-c3nnn[nH]3)n2)nc(-c2cccc(-c3nnn[nH]3)n2)c1</smiles><smiles>OC(c1nnn[nH]1)(c1nnn[nH]1)c1nnn[nH]1</smiles>

6<smiles>c1ccc(-c2cccc(-c3nnn[nH]3)n2)nc1</smiles>

9<smiles>Cn1c(-c2cccc(-c3nnn[nH]3)n2)nc2ccccc21</smiles>

12
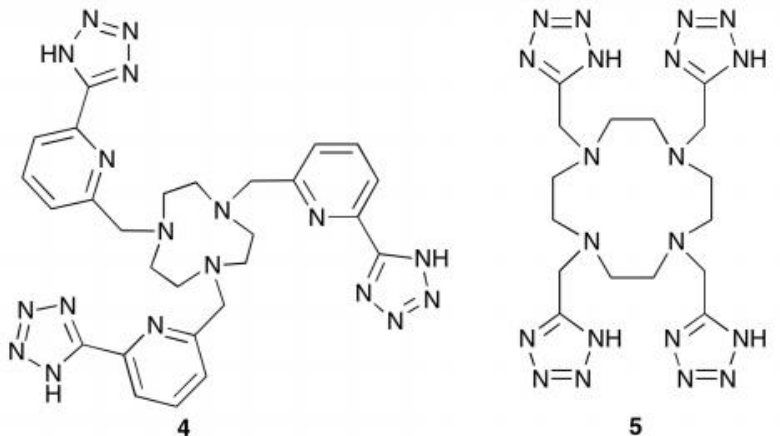<smiles>[R]c1cc(-c2nnn[nH]2)nc(-c2nnn[nH]2)c1</smiles>

7

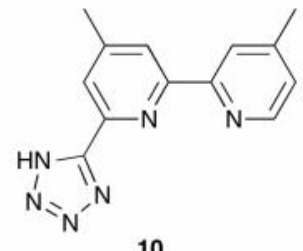

10<smiles>Oc1cccc2ccc(-c3nnn[nH]3)nc12</smiles>

13

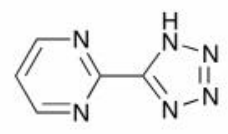

15<smiles>O=C(O)c1cccc(-c2nnn[nH]2)n1</smiles>

8<smiles>c1cnc2c(c1)ccc1ccc(-c3nnn[nH]3)nc12</smiles><smiles>O=C(O)Cn1nnnc1Nc1nnnn1CC(=O)O</smiles>

14

Figure 2. Tetrazole ligands used in lanthanoid complexes where tetrazole-Ln interactions are limited to the first coordination sphere: $\mathbf{3},[22,23], \mathbf{4},[22] \mathbf{5 , [ 2 4 ]} \mathbf{6 , [ 2 5 ] ~ 7 , [ 1 9 - 2 1 ] ~ 8 , [ 1 9 ] ~ 9 , [ 2 6 ] ~ 1 0 , [ 2 7 , ~ 2 8 ] ~ 1 1 , [ 2 9 ] ~ 1 2 , [ 3 0 ] ~ 1 3 , [ 3 1 ] , ~}$ 14,[32] 15.[33, 34]

A recent study of the tetrazole analogue of the widely studied DOTA macrocyclic ligand, 5, provides an interesting comparison of tetrazolate and carboxylate as donor groups.[24] Structurally, the lanthanoid complexes were found to be very similar, but replacing carboxylate with tetrazolate reduced the stability constant of the gadolinium complex from $\log K$ of 24.1 to 16.6 . This reduction in thermodynamic stability was somewhat compensated by an increase in kinetic inertness of the tetrazolato complex by two orders of magnitude.[24] The gadolinium complex of 5 was successfully used as an MRI contrast agent. This work shows that tetrazolate analogues of carboxylate ligands can form usefully stable complexes in highly competitive solvent systems, at least in some cases, despite the replacement of $\mathrm{O}$ donor atoms with $\mathrm{N}$ atoms.

The only two bidentate ligands that form complexes with exclusively first coordination sphere interaction with a lanthanoid cation are 14 and $\mathbf{1 5}$. The ligand 14 bridges lanthanoid cations through the bidentate interaction with tetrazole $\mathrm{N}$ atoms, and the two carboxylate groups to form a three-dimensional coordination network.[32] 5- 
(Pyrimidyl)-tetrazolate, 15, on the other hand, acts as a bis-bidentate bridging ligand where the tetrazole group interacts only the first coordination sphere of two lanthanoid cations, with no second sphere interactions.[33, 34] The complex cation from one of these structures is shown in Figure 3. This $\mu_{1,4}$-bridging mode is rare, but is also observed in a Pr complex of the deprotonated form of 20 (Figure 4),[35] where the bridging tetrazole moiety is involved in additional second sphere interactions. Indeed, first coordination sphere bridging of lanthanoids by tetrazolato ligands is uncommon in any form. The only other examples beyond those mentioned above are a $\mu_{1,2}$-bridge in a Dy complex of the deprotonated form of $\mathbf{1 9 , [ 3 6 ] ~ a ~} \mu_{1,3}$-bridge in a La complex of azo-linked bis-tetrazolate 18,[37] and $\mu_{1,2,3}$-bridges in a range of $\operatorname{Ln}_{19}$ and $\operatorname{Ln}_{12}$ clusters supported by the bistetrazolate calixarene 29,[38] (see Figure 4 for ligand structures).

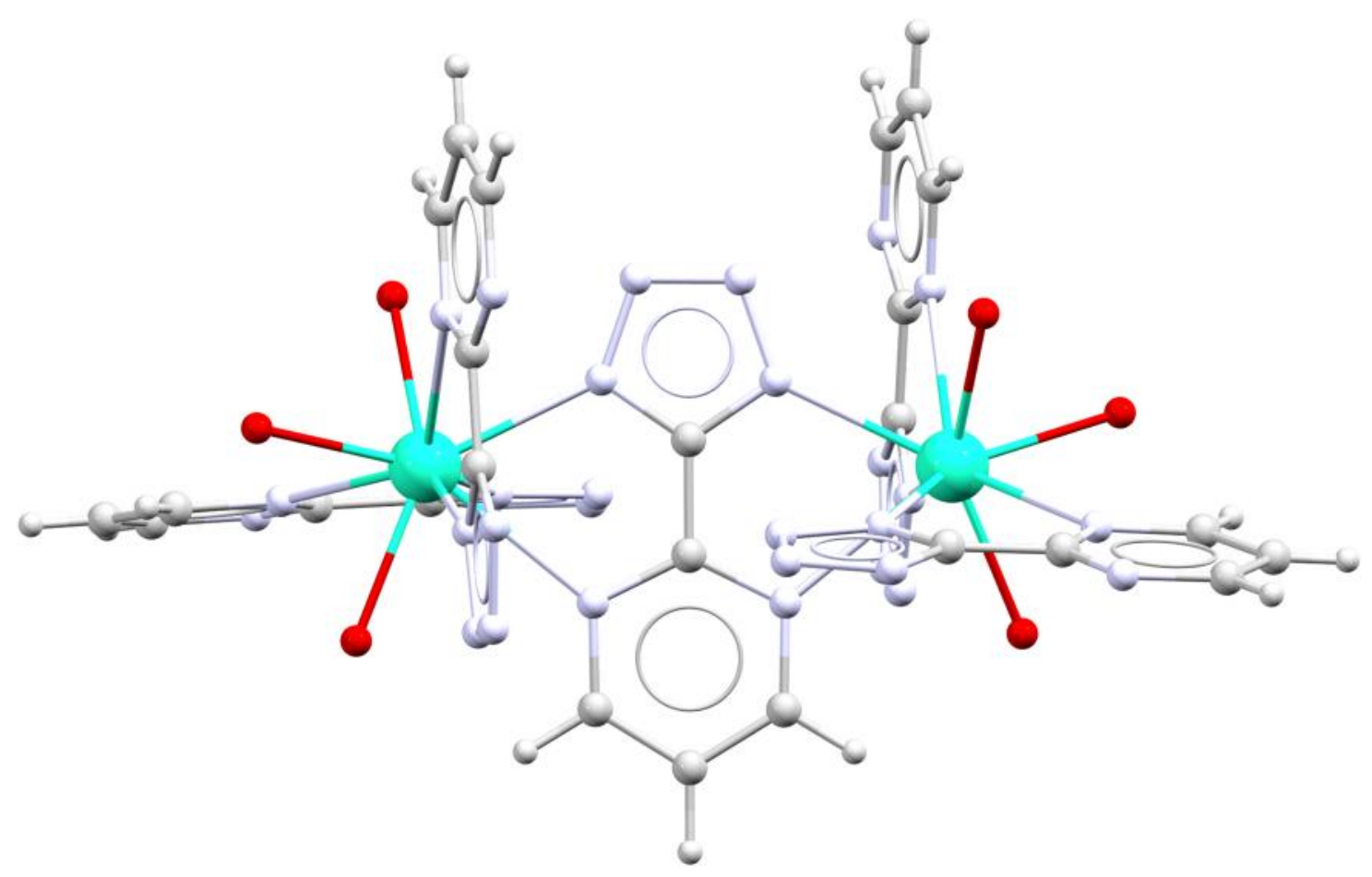

Figure 3. A representation of the complex cation from the compound $\left[\mathrm{Dy}_{2}(\mathbf{1 5}-\mathrm{H})_{4}(\mu-(\mathbf{1 5}-\mathrm{H}))\left(\mathrm{H}_{2} \mathrm{O}\right)_{6}\right](\mathbf{1 5}-$

$\mathrm{H}) \cdot 6 \mathrm{H}_{2} \mathrm{O}$ emphasising the bridging of the metal ions in the first coordination sphere.[33]

\section{Tetrazolate moiety bridging metal atoms from the first to the second coordination sphere}

There are a significant number of complexes where an anionic tetrazolate moiety bridges from the first to the second coordination sphere of a lanthanoid cation. Once again, in the majority of cases, a ligand must be at least bidentate to achieve interaction with the first coordination sphere (Figure 4). Bridging to the second coordination sphere through hydrogen bonds to aqua ligands occurs in a number of modes, the most common of which is a double hydrogen bond bridge between N3 and N4 to two O atoms (Figure 5, Mode 1). Single hydrogen bond bridges to one or more of the $\mathrm{N}$ atoms not bound directly to the Ln atom are also common but are rarely the only interaction observed.

The complexes of 5-(2-pyridyl)tetrazolate (16-H) are a good example of such interactions. Neutral [Ln(16$\mathrm{H})_{3}\left(\mathrm{H}_{2} \mathrm{O}\right)_{3}$ ] complexes have been reported for La,[39] Gd,[40] Eu,[41] Tb,[41] and Ho[42]. Cationic [Ln((16$\left.\mathrm{H})_{2}\left(\mathrm{H}_{2} \mathrm{O}\right)_{x}\right]^{+}$are known for $\mathrm{La}, \mathrm{Gd}$, and $\mathrm{Ho}$, as well as neutral hydroxo bridged dimer for $\mathrm{Yb}$ and $\mathrm{Y}$, proposed to 
arise through condensation of the cationic species.[42] Figure 6 shows a fragment of the structure of [Gd(16$\left.\mathrm{H})_{2}\left(\mathrm{H}_{2} \mathrm{O}\right)_{5}\right] \mathrm{Cl}$ as an example of a Mode 1 type of interaction, with the two hydrogen bonds presumably forming a strong link between the two cationic centres. The one-dimensional polymer thus formed is further cross-linked by single hydrogen bonds (Mode 2, Figure 5) such that all tetrazolate $\mathrm{N}$ atoms in the structure are involved in second sphere interactions.

Similar interactions are seen in an isomorphous series of complexes, $\left[\mathrm{Ln}(\mathbf{2 4}-2 \mathrm{H})(\mathrm{HCOO})\left(\mathrm{H}_{2} \mathrm{O}\right)_{3}\right],(\mathrm{Ln}=\mathrm{Pr}, \mathrm{Gd}$, $\mathrm{Eu}, \mathrm{Tb}, \mathrm{Dy}, \mathrm{Er}, \mathrm{Yb}$ ) (Figure 7) contributing to the formation of a two dimensional hydrogen bonded polymer, with the three dimensional structure completed by formate bridges between the metal ions.[43]

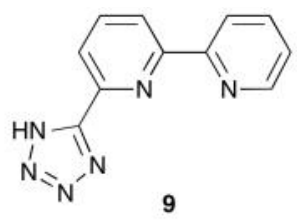<smiles>N(=N/c1nnn[nH]1)\c1nnn[nH]1</smiles>

18<smiles>c1cnc(-c2nnn[nH]2)nc1</smiles>

22<smiles>c1cc(-c2ccnc(-c3nnn[nH]3)n2)nc(-c2nnn[nH]2)c1</smiles>

26
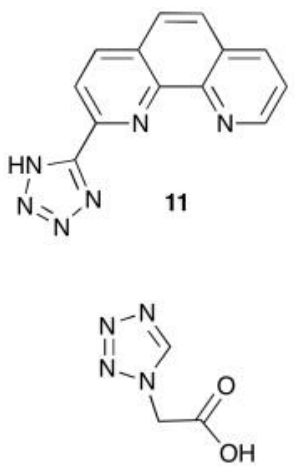

19

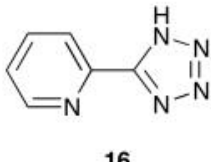

16<smiles>O=C(O)c1nnn[nH]1</smiles>

20

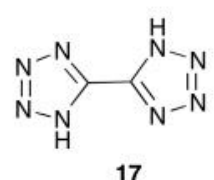<smiles>O=C(O)c1cc(C(=O)O)cc(-c2nnn[nH]2)c1</smiles><smiles>N(=N/c1nnn[nH]1)\Nc1nnn[nH]1</smiles>

23<smiles>c1nc(-c2nnn[nH]2)c(-c2nnn[nH]2)[nH]1</smiles>

27<smiles>n1n[nH]c(Nc2nnn[nH]2)n1</smiles>

24

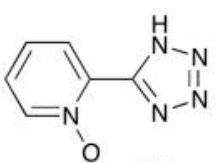

O 25

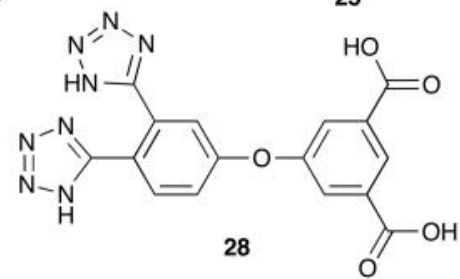

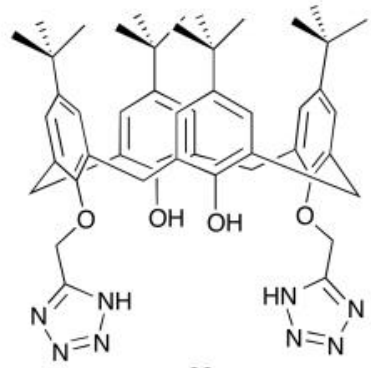

29

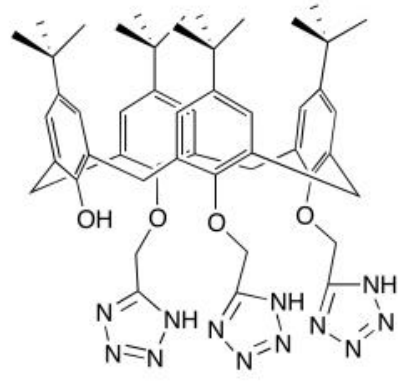

30

Figure 4. Tetrazole ligands found in lanthanoid complexes where tetrazole-Ln interactions bridge the first and second coordination spheres: 9,[27, 44] 11,[29] 16,[39-42] 17,[45] 18,[37, 46, 47] 19,[36, 48] 20,[35] 21,[49]

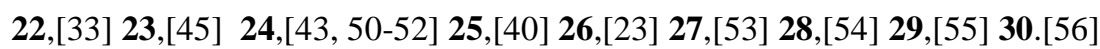

Examples where bridging Mode 1 is not observed include those where there is only a single aqua ligand bound

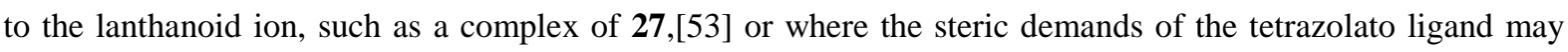
make such an approach unviable (such as complexes of $\mathbf{2 2 , [ 3 3 ] ~ 2 6 , [ 2 3 ] ~ 2 1 , [ 4 9 ] ~ 9 , [ 4 4 ] ~ a n d ~ 2 9 . [ 5 5 ] ) . ~ O t h e r s ~}$ 
display a related convergent motif, but bridging to two linked lanthanoid cations (Mode 3, Figure 5). This is observed, for example, in complexes of 18,[37] 19,[36, 48], and 20.[35] Nevertheless, of the $~ 50$ structures found on the Cambridge Structural Database where tetrazole moieties bridge the first and second coordination spheres, bridging Mode 1 (Figure 5) is found in almost three quarters of these, suggesting this is a favoured structural motif.

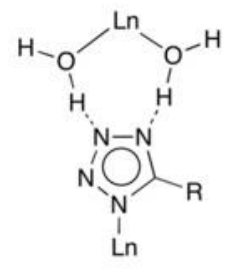

Mode 1
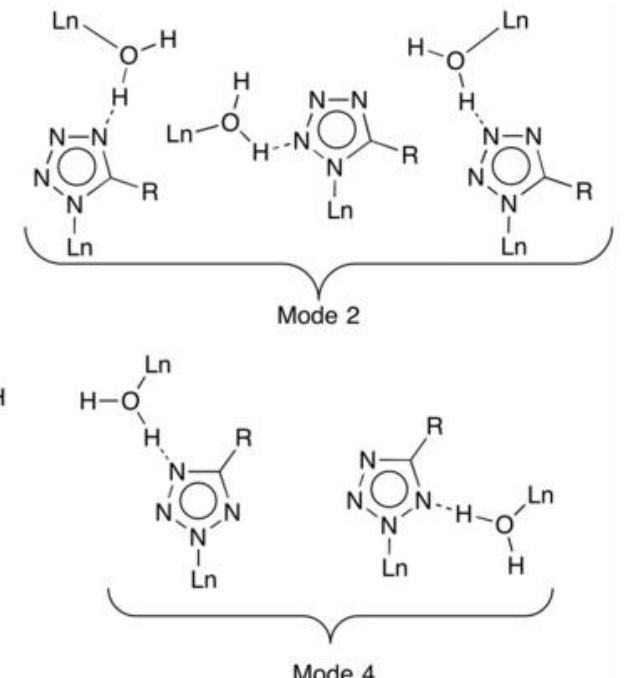

Figure 5. Bridging modes observed where tetrazole ligands bridge the first and second coordination spheres of lanthanoid cations.

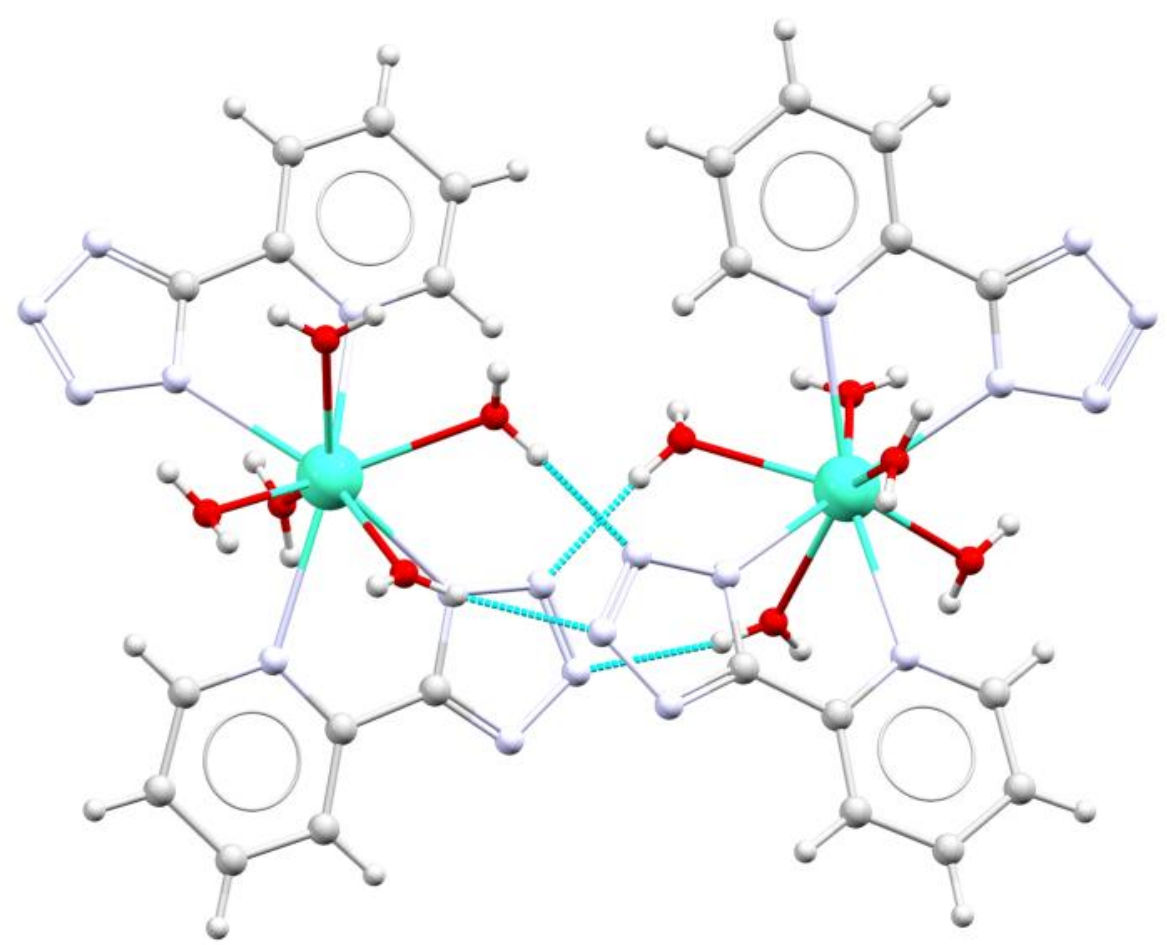

Figure 6. The hydrogen bond linked dimer found in the structure of $\left[\mathrm{Gd}(\mathbf{1 6}-\mathrm{H})_{2}\left(\mathrm{H}_{2} \mathrm{O}\right)_{5}\right] \mathrm{Cl}$.[42] 


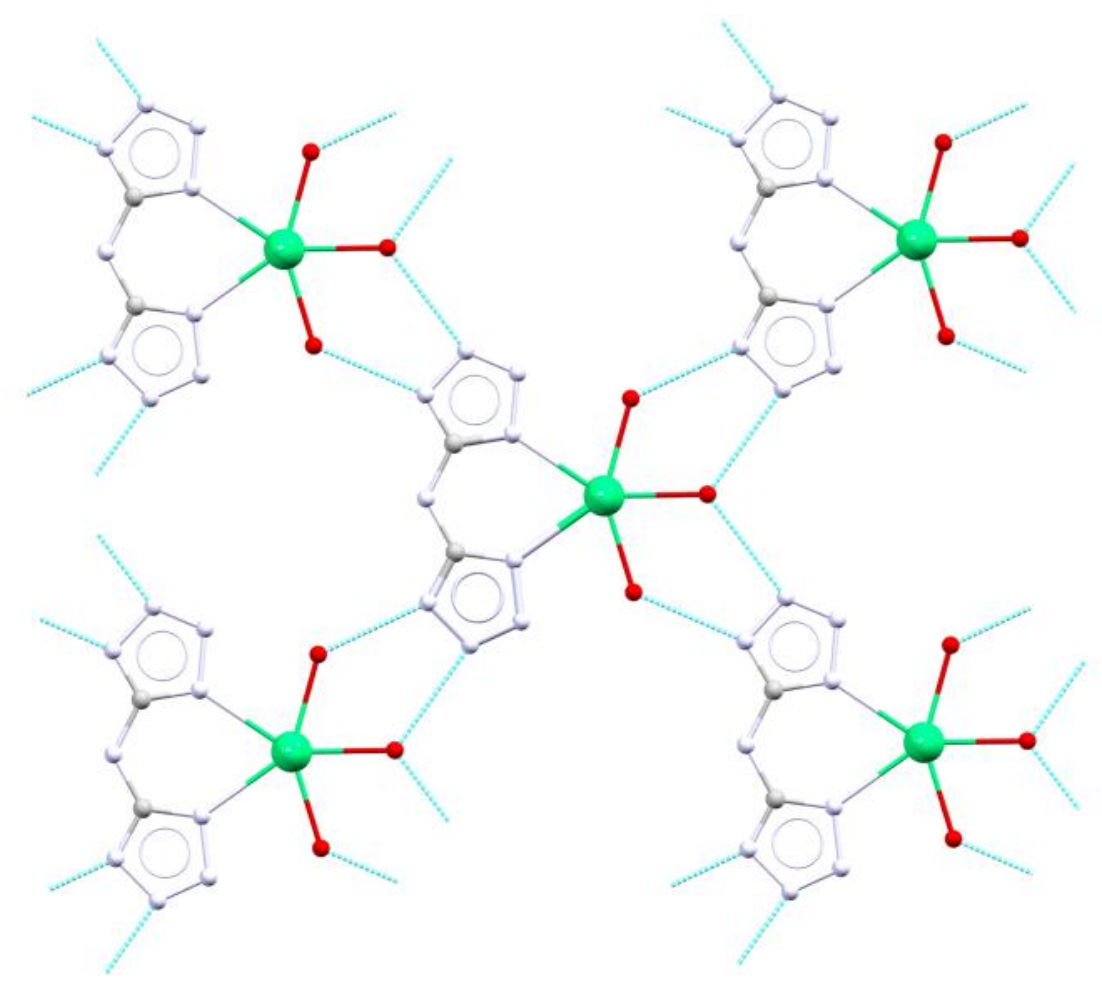

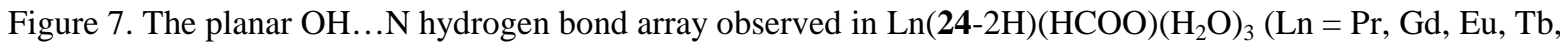
$\mathrm{Dy}, \mathrm{Er}, \mathrm{Yb}$ ) formed by tetrazole bridges between the first and second coordination spheres. The formate anions in the axial positions of the distorted pentagonal bipyramidal coordination sphere have been omitted for clarity.[43]

While this ligand set is dominated by polydentate ligands, it is notable that two ligands, $\mathbf{1 7}$ and $\mathbf{1 8}$, are found in some instances with a rare unidentate tetrazolate moiety coordinated to a lanthanoid cation, without a supporting chelated donor atom. The isomorphous dinuclear $\mathrm{La}$ and $\mathrm{Ce}$ complexes of $\mathbf{1 7}$ include a chelated ligand bound by the N1 and N1' atoms, and a bridging ligand linked through the N2 and N2' atoms (Figure 8).[45] Here, it may be relevant that a water solvent molecule bridges between a chelated tetrazole ligand and the bridging tetrazole group (Figure 8), although this is only one of an extensive range of hydrogen bond interactions in the structure.

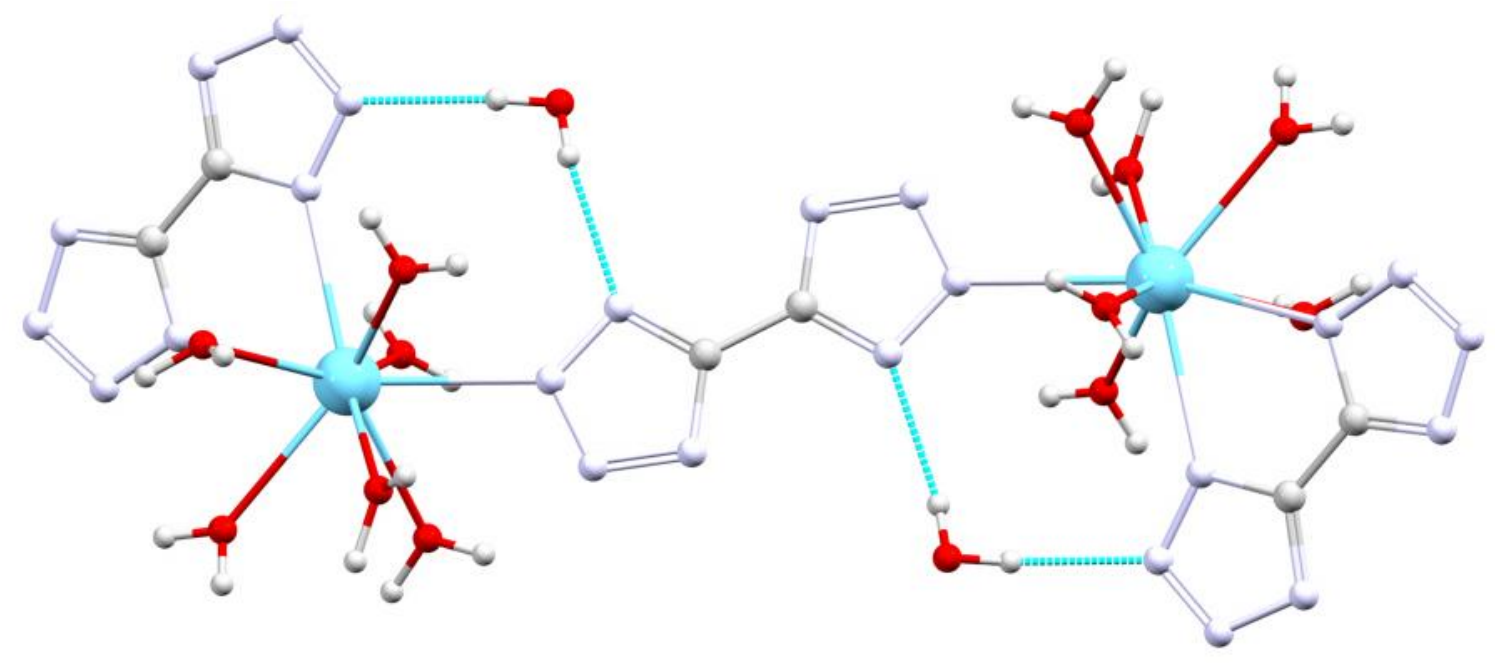


Figure 8. The dimeric structure observed in $\left[\mathrm{La}_{2}(\mathbf{1 7}-2 \mathrm{H})_{3}\left(\mathrm{OH}_{2}\right)_{12}\right] \cdot 2 \mathrm{H}_{2} \mathrm{O}$ showing the water molecule in the second sphere linking the unidentate tetrazole moiety to a neighbouring tetrazole group. [45]

In the case of 18, a dimeric La complex has a unidentate tetrazolate group supported by a second sphere interaction with an aqua ligand on the second metal ion (Figure 9), possibly also with an approach between an azo $\mathrm{N}$ atom and the cation ( $\mathrm{La}-\mathrm{N}_{\mathrm{azo}}, 2.98 ; \mathrm{Ln}-\mathrm{N}_{\text {tet }}, 2.69 \AA$ ).[37] In contrast, a mononuclear Gd complex of 18 is reported with a second sphere interaction between an aqua ligand, and the unbound tetrazolate group of $\mathbf{1 8}$ (Figure 10).[46] An arguably similar interaction occurs in the praseodymium complex of tris-tetrazole substituted calixarene 30, which was found to act as a unidentate ligand with a single Pr-N bond, which is supported by four hydrogen bonds between the neighbouring tetrazole groups and aqua ligands (Figure 11).[56]

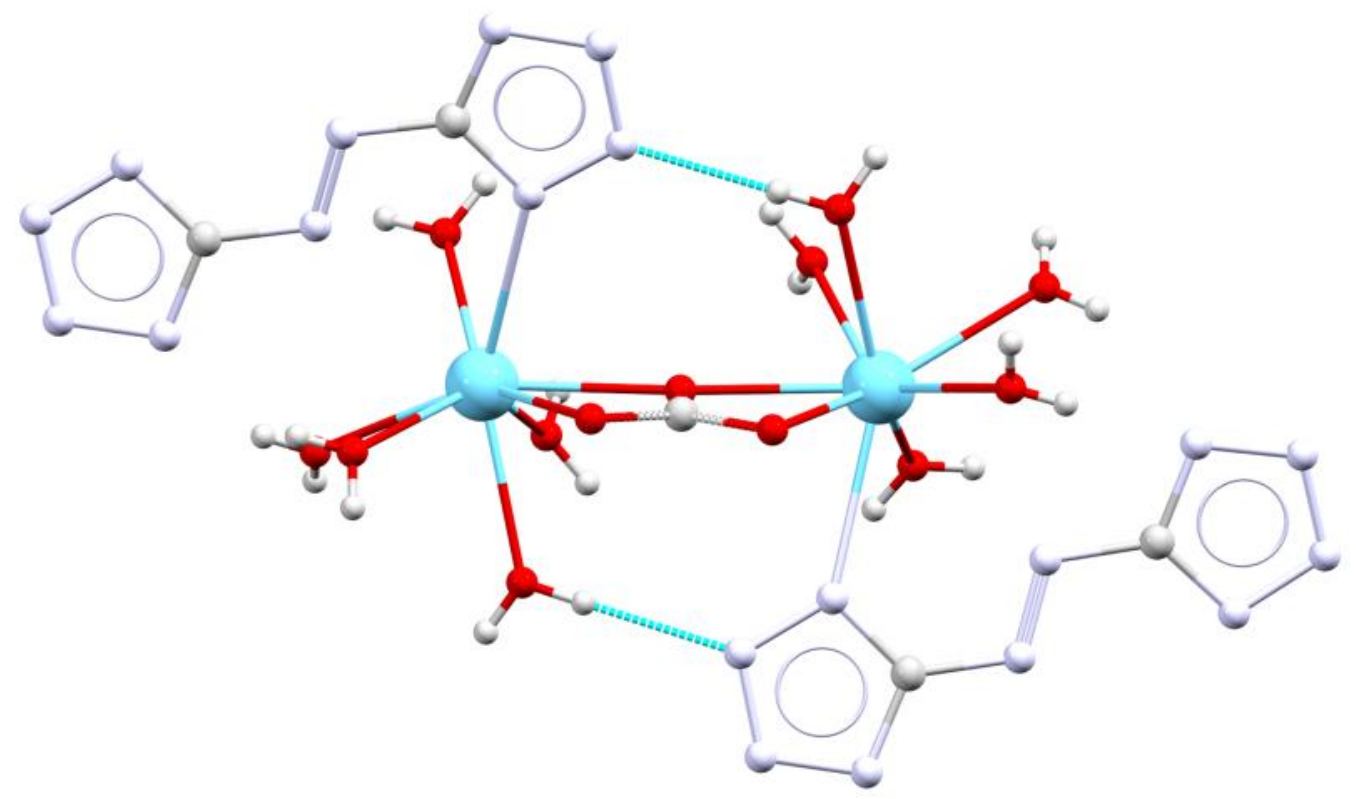

Figure 9. The carbonato-bridged dimeric structure $\left[\mathrm{La}_{2}(\mathbf{1 8}-2 \mathrm{H})_{2}\left(\mathrm{H}_{2} \mathrm{O}\right)_{5}\left(\mathrm{CO}_{3}\right)\right] \cdot \mathrm{H}_{2} \mathrm{O}$, emphasising the second sphere interaction with a unidentate tetrazole moiety.[37] 


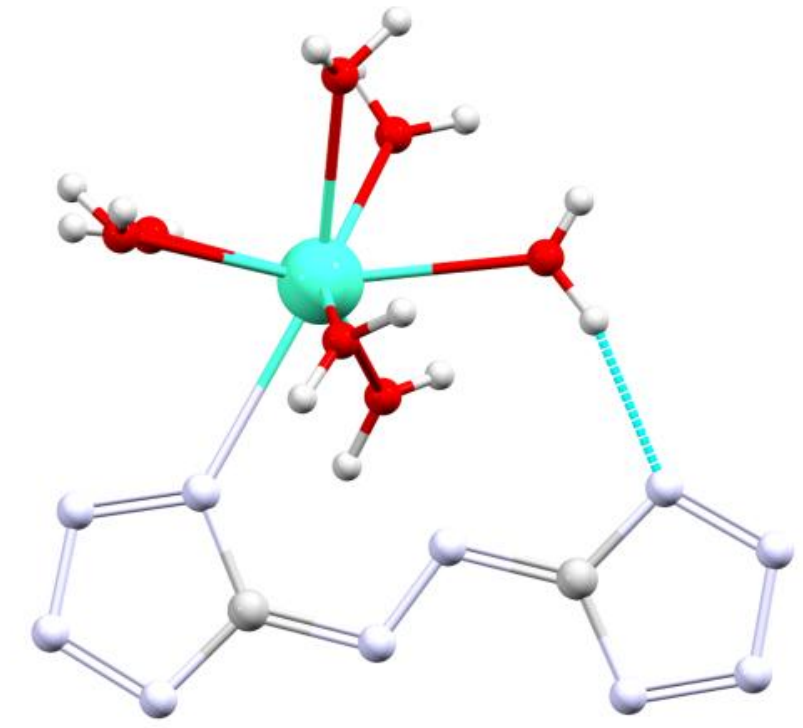

Figure 10. A view of the complex cation $\left[\mathrm{Gd}\left(\mathrm{H}_{2} \mathrm{O}\right)_{7}(\mathbf{1 8}-2 \mathrm{H})\right]^{+}$emphasising the second sphere interaction between an aqua ligand and the unbound tetrazole moiety, presumably adding stability to the unidentate tetrazole-metal interaction. [46] 


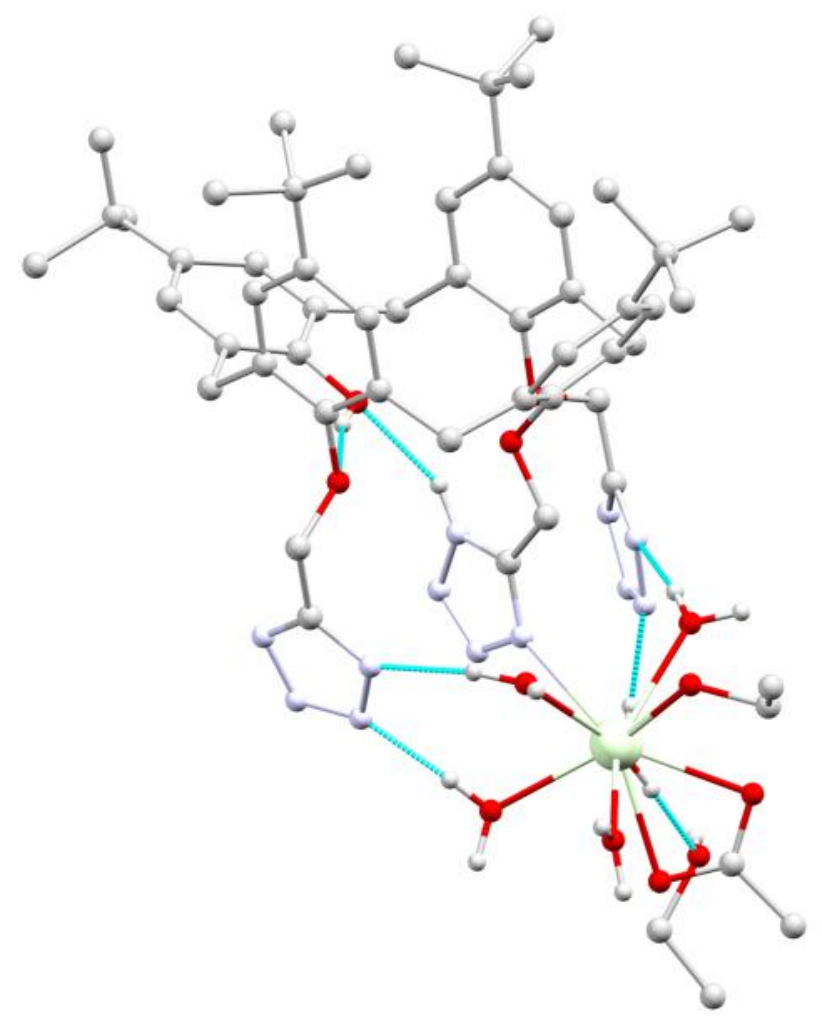

Figure 11. The praseodymium complex of 30, $\left.\mathrm{Pr}(\mathbf{3 0}-2 \mathrm{H})(\mathrm{OAc})\left(\mathrm{OH}_{2}\right)_{5}(\mathrm{EtOH})\right]$, showing unidentate first coordination sphere interaction of a tetrazole group, supported by second sphere interactions involving neighboring tetrazole moieties.[56]

\section{Tetrazole moiety in the second coordination sphere only}

Where tetrazole or tetrazolate groups interact with only the second sphere of the lanthanoid cation, bridging occurs in the majority of examples. Exceptions predominantly involve ligands that are $\mathrm{N}$-alkylated with coordinating groups (see for example 19,[57, 58] 31,[59] 36,[60, 61] Figure 12) that are directly coordinated to a neighbouring metal centre. Some N-alkylated tetrazole ligands exhibit no interaction with the lanthanoid centre, with the tetrazole moiety functioning purely as a linker of the coordinating groups. Complexes of the meta isomer of ligands $\mathbf{3 3}$ and $\mathbf{3 5}$ exhibit this behaviour, for example.[62, 63] In other cases where no first or second sphere interactions are observed, the tetrazole moiety is coordinated to a d-block metal ion limiting further interactions $(39[64])$, or the system is anhydrous such as found in luminescent metal organic frameworks constructed with 5-(4-(tetrazol-5-yl)phenyl) isophthalic acid.[65]

When tetrazole groups bridge the second coordination spheres of neighbouring lanthanoid cations, the majority of structures involve at least one double hydrogen bond interaction (Mode 1, Figure 4). The bridge is often completed by a single hydrogen bond link (Mode 5, Figure 13). The extensive hydrogen bond networks in these structures typically also include single hydrogen bond bridges between lanthanoid centres. Less commonly observed are structures that exhibit bridging Mode 6 (Figure 13), with four hydrogen bonds stabilising the second sphere interaction. This mode is observed in complexes of 38,[61] whereas the related Mode 7 (Figure 13) is observed in complexes of the dicarboxylate 21.[66] Bridging Mode 6 is also observed in complexes of ligands free of oxygen donor atoms, with 16, and 18. The impact of these interactions on the properties of the 
complexes is difficult to deconvolute from other factors, given the relatively small number of structures available for analysis. It is interesting to note that a "water-poor" Dy complex of deprotonated 18[67] is found to be unusually thermally stable. The structure is free of uncomplexed water, and has extensive hydrogen bond linkages between the $\left[\mathrm{Dy}\left(\mathrm{H}_{2} \mathrm{O}\right)_{8}\right]^{3+}$ ions and the $\mathbf{1 8}$ anions, with Mode 6 linkages between the metal centres, along with additional hydrogen bonds to the azo $\mathrm{N}$ atoms (Figure 14). It should be noted, however, that studies of the retention of crystallinity upon dehydration of a range of complexes of the bis-tetrazole substituted benzene derivatives $\mathbf{4 4}$ and $\mathbf{4 5}$ resulted in the proposal that the presence or absence of strong $\pi$-stacking between the ligands, in addition to extensive hydrogen bonded networks, was the deciding factor.[68-70]

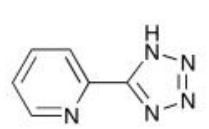

16

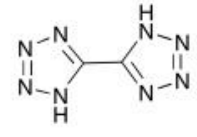

17<smiles>N(=N/c1nnn[nH]1)\c1nnn[nH]1</smiles>

18

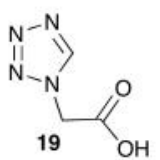<smiles>O=C(O)c1cc(C(=O)O)cc(-c2nnn[nH]2)c1</smiles><smiles>Nc1nnnn1CC(=O)O</smiles>

31<smiles>Nc1nnnn1CCC(=O)O</smiles>

32<smiles>O=C(O)Cn1nnc(-c2ccccn2)n1</smiles>

33<smiles>O=C(O)c1nnn[nH]1</smiles>

20<smiles>O=C(O)Cn1nnc(-c2ncccn2)n1</smiles>

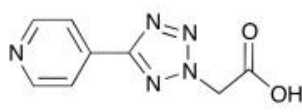

35<smiles>O=C(O)Cn1nnc(-c2cnccn2)n1</smiles>

36<smiles>O=C(O)c1ccc(-c2nnn[nH]2)cc1</smiles>

40<smiles>c1cc(-c2nnn[nH]2)cc(-c2nnn[nH]2)c1</smiles>

44<smiles>O=C(O)CN1C=CC(c2nnn[nH]2)=CC1</smiles>

37<smiles>O=C(O)c1cc(/N=N/c2nnn[nH]2)ccc1O</smiles>

41

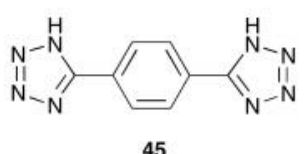<smiles></smiles>

38<smiles>O=C(O)c1cccc(-c2nnn[nH]2)c1</smiles>

42<smiles>O=C(O)c1cccc(-c2ccc(-c3nnn[nH]3)cc2)c1</smiles>

39<smiles>O=C(O)c1cc(Oc2ccc(-c3nnn[nH]3)cc2)cc(C(=O)O)c1</smiles>

Figure 12. Tetrazole ligands found in lanthanoid complexes where tetrazole-Ln interactions involve only the second coordination sphere: 16,[71] 17,[45] 18,[37, 47, 67] 19,[57, 58, 72, 73] 20,[34] 21,[66, 74, 75] 31,[59, 76] 32,[32, 77, 78] 33,[79] 34,[80] 35,[63, 79, 81, 82] 36,[60, 61, 80, 82] 37,[83] 38,[61, 62, 78, 82] 39,[64] $\mathbf{4 0},[84] 41,[85,86] \mathbf{4 2},[87-89] 43,[90] 44,[68,69,91] 45,[70] 46,[37]$. 

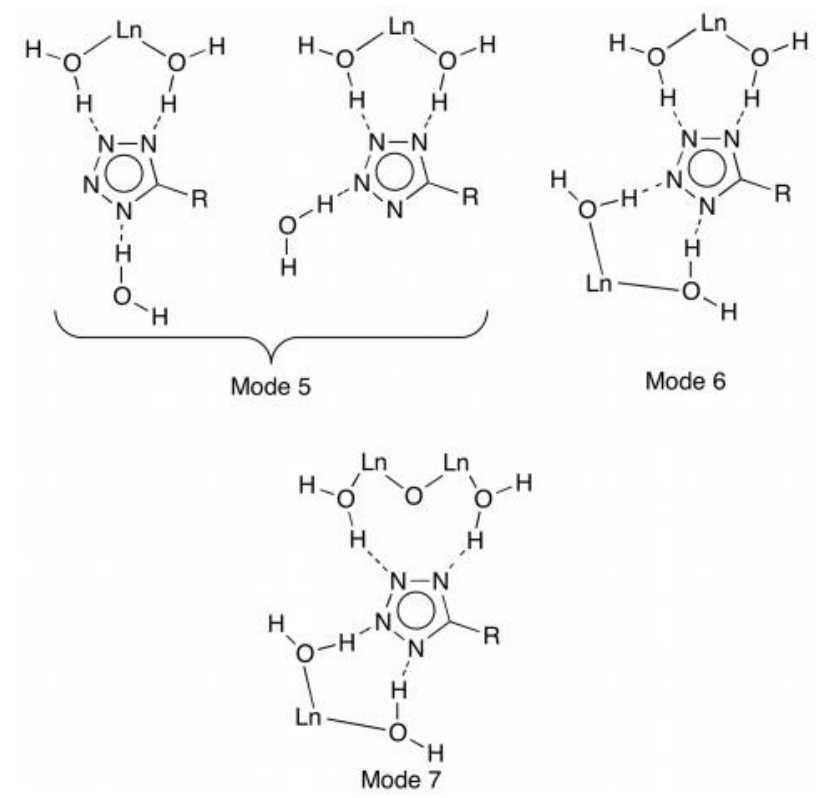

Figure 13. Some of the second sphere bridging modes observed in lanthanoid tetrazolate complexes.

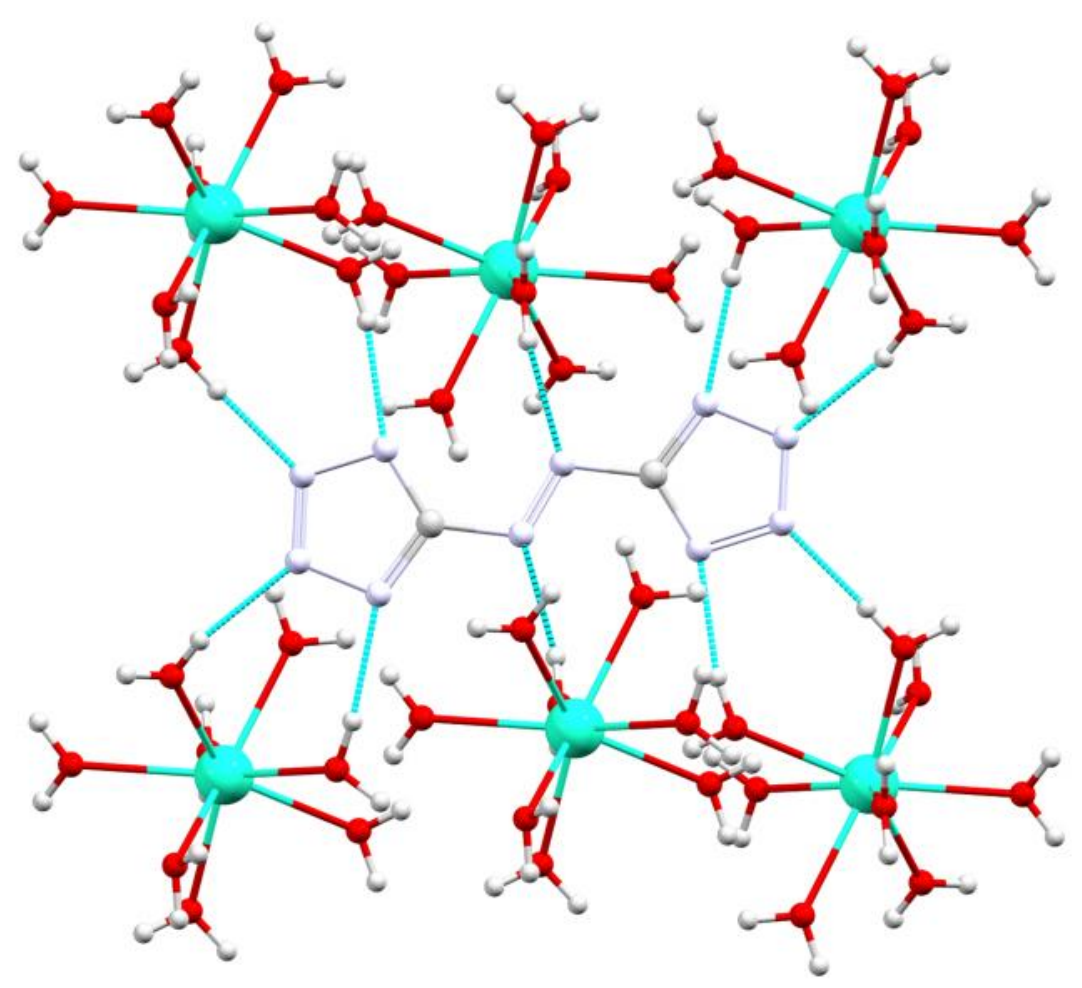

Figure 14. A fragment of the Dy salt $\left[\mathrm{Dy}\left(\mathrm{H}_{2} \mathrm{O}\right)_{8}\right]_{2}(\mathbf{1 8}-2 \mathrm{H})_{3}$, emphasising the hydrogen bond bridges between the tetrazole moieties and aqua ligands.[67]

\section{Conclusions}

The substitution of tetrazolate for carboxylate donor groups in polydentate lanthanoid ionophores has been shown to produce complexes with promising properties, particularly for light emission. While such complexes are generally found to be less thermodynamically stable due to the replacement of $\mathrm{O}$ donor atoms with $\mathrm{N}$ atoms, 
in at least one case this is compensated for by increased kinetic inertness. Bidentate and unidentate tetrazolatebased ligands are found almost exclusively in the second sphere of hydrated lanthanoid cations. Second sphere interactions are hindered where the tetrazole moiety is $\mathrm{N}$-alkylated, such that the dominant function of the tetrazole moiety is to link other donor groups. The extensive range of hydrogen bond interactions beween the tetrazole moiety and aqua ligands are complex, but certain motifs are regularly observed in the solid-state. Given the directionality and stability of hydrogen bonds, and the rigid ligand structures that are readily accessible, crystal engineering with these components is a viable possibility worthy of further exploration.

\section{Acknowledgements}

MM is the recipient of an Australian Research Council Future Fellowship (project number FT130100033).

\section{References}

[1] G. Aromi, L.A. Barrios, O. Roubeau, P. Gamez, Coord. Chem. Rev., 255 (2011) 485-546.

[2] E.A. Popova, R.E. Trifonov, V.A. Ostrovskii, Arkivoc, (2012) 45-65.

[3] M.A. Malik, M.Y. Wani, S.A. Al-Thabaiti, R.A. Shiekh, J. Inclusion Phenom. Macrocyc. Chem., 78 (2014) 15-37.

[4] S.V. Eliseeva, J.C.G. Bunzli, New J. Chem., 35 (2011) 1165-1176.

[5] R.N. Butler, Tetrazoles, in: R.C. Storr (Ed.) Comprehensive Heterocyclic Chemistry II, Pergamon Press, Oxford, UK, 1996, pp. 621-678.

[6] R.J. Herr, Biorg. Med. Chem., 10 (2002) 3379-3393.

[7] J. Roh, K. Vávrová, A. Hrabálek, Eur. J. Org. Chem., 2012 (2012) 6101-6118.

[8] H. Zhao, Z.R. Qu, H.Y. Ye, R.G. Xiong, Chem. Soc. Rev., 37 (2008) 84-100.

[9] W.A. Finnegan, R.A. Henry, R.J.A.C.S. Lofquist, 80, 3908, J. Am. Chem. Soc., 80 (1958) 3908-3911. [10] V.A. Ostrovskii, E.A. Popova, R.E. Trifonov, Advances in Heterocyclic Chemistry, Vol 123, 123 (2017) 162.

[11] K. Koguro, T. Oga, S. Mitsui, R. Orita, Synthesis-Stuttgart, (1998) 910-914.

[12] Z.P. Demko, K.B. Sharpless, J. Org. Chem., 66 (2001) 7945-7950.

[13] D. Amantini, R. Beleggia, F. Fringuelli, F. Pizzo, L. Vaccaro, J. Org. Chem., 69 (2004) 2896-2898.

[14] A.N. Chermahini, M.K. Omran, H.A. Dabbagh, G. Mohammadnezhad, A. Teimouri, New J. Chem., 39 (2015) 4814-4820.

[15] F. Himo, Z.P. Demko, L. Noodleman, K.B. Sharpless, J. Am. Chem. Soc., 124 (2002) 12210-12216.

[16] D.A. Beauchamp, S.J. Loeb, Chemistry - A European Journal, 8 (2002) 5084-5088.

[17] W.J. Evans, D.K. Drummond, L.A. Hughes, H.M. Zhang, J.L. Atwood, Polyhedron, 7 (1988) 1693-1703.

[18] X.G. Zhou, Z.E. Huang, R.F. Cai, L.X. Zhang, X.F. Hou, X.J. Feng, X.Y. Huang, J. Organomet. Chem., 563 (1998) 101-112.

[19] E.S. Andreiadis, D. Imbert, J. Pecaut, R. Demadrille, M. Mazzanti, Dalton Trans., 41 (2012) 1268-1277.

[20] K.S. Kumar, B. Schafer, S. Lebedkin, L. Karmazin, M.M. Kappes, M. Ruben, Dalton Trans., 44 (2015) 15611-15619.

[21] S. Di Pietro, N. Gautier, D. Imbert, J. Pecaut, M. Mazzanti, Dalton Trans., 45 (2016) 3429-3442.

[22] M. Giraud, E.S. Andreiadis, A.S. Fisyuk, R. Demadrille, J. Pecaut, D. Imbert, M. Mazzanti, Inorg. Chem., 47 (2008) 3952-3954.

[23] E.S. Andreiadis, R. Demadrille, D. Imbert, J. Pecaut, M. Mazzanti, Chem. Eur. J., 15 (2009) 9458-9476.

[24] A. Boltjes, A. Shrinidhi, K. van de Kolk, E. Herdtweck, A. Domling, Chem. Eur. J., 22 (2016) 7352-+.

[25] H.C. Hu, X.M. Kang, C.S. Cao, P. Cheng, B. Zhao, Chem. Commun., 51 (2015) 10850-10853.

[26] H.R. Wen, F.Y. Liang, Z.G. Zou, S.J. Liu, J.S. Liao, J.L. Chen, Inorg. Chem. Commun., 79 (2017) 41-45.

[27] J.L. Chen, Y.S. Luo, G.P. Gao, J.L. Zhao, L. Qiu, N. Liu, L.H. He, S.J. Liu, H.R. Wen, Polyhedron, 117 (2016) 388-393.

[28] B.-S. Di, Y.-S. Luo, X.-H. Zeng, L.-H. He, J.-L. Chen, J.-S. Liao, S.-J. Liu, H.-R. Wen, Chin. J. Inorg. Chem., 33 (2017) 323.

[29] J.R. Jimenez, I.F. Diaz-Ortega, E. Ruiz, D. Aravena, S.J.A. Pope, E. Colacio, J.M. Herrera, Chem. Eur. J., 22 (2016) 14548-14559.

[30] N.M. Shavaleev, S.V. Eliseeva, R. Scopelliti, J.C. Bunzli, Inorg. Chem., 53 (2014) 5171-5178.

[31] G. Bozoklu, C. Marchal, J. Pecaut, D. Imbert, M. Mazzanti, Dalton Trans., 39 (2010) 9112-9122. 
[32] L. Shen, Y.T. Min, J. Wang, Y. Xu, H.J. Chen, J. Yang, X. Zhang, M.L. Wu, G.W. Yang, B. Wei, Z. Anorg. Allg. Chem., 642 (2016) 174-181.

[33] A. Rodriguez-Dieguez, A.J. Mota, J.M. Seco, M.A. Palacios, A. Romerosa, E. Colacio, Dalton Trans., (2009) 9578-9586.

[34] A. Rodríguez-Diéguez, A. Salinas-Castillo, A. Sironi, J.M. Seco, E. Colacio, CrystEngComm, 12 (2010) 1876.

[35] M.-F. Wu, M.-S. Wang, S.-P. Guo, F.-K. Zheng, H.-F. Chen, X.-M. Jiang, G.-N. Liu, G.-C. Guo, J.-S. Huang, Cryst. Growth Des., 11 (2011) 372-381.

[36] Q.-Y. Li, D.-Y. Chen, M.-H. He, G.-W. Yang, L. Shen, C. Zhai, W. Shen, K. Gu, J.-J. Zhao, J. Solid State Chem., 190 (2012) 196-201.

[37] G. Steinhauser, G. Giester, N. Leopold, C. Wagner, M. Villa, A. Musilek, Helv. Chim. Acta, 93 (2010) 183-202.

[38] D. D'Alessio, A.N. Sobolev, B.W. Skelton, R.O. Fuller, R.C. Woodward, N.A. Lengkeek, B.H. Fraser, M. Massi, M.I. Ogden, J. Am. Chem. Soc., 136 (2014) 15122-15125.

[39] P.C. Andrews, P.C. Junk, M. Massi, M. Silberstein, Chem. Commun., (2006) 3317-3319.

[40] A. Facchetti, A. Abbotto, L. Beverina, S. Bradamante, P. Mariani, C.L. Stern, T.J. Marks, A. Vacca, G.A. Pagani, Chem. Commun., (2004) 1770-1771.

[41] Y.-S. Zhou, D.-H. Xu, L.-J. Zhang, Chem. Res. Chin. Univ., 26 (2010) 866.

[42] P.C. Andrews, T. Beck, B.H. Fraser, P.C. Junk, M. Massi, Polyhedron, 26 (2007) 5406-5413.

[43] J.M. Lin, Y.F. Guan, D.Y. Wang, W. Dong, X.T. Wang, S. Gao, Dalton Trans., (2008) 6165-6169.

[44] J. Kratsch, B.B. Beele, C. Koke, M.A. Denecke, A. Geist, P.J. Panak, P.W. Roesky, Inorg. Chem., 53 (2014) 8949-8958.

[45] P.J. Eulgem, A. Klein, N. Maggiarosa, D. Naumann, R.W. Pohl, Chem. Eur. J., 14 (2008) 3727-3736.

[46] G. Steinhauser, G. Giester, N. Leopold, C. Wagner, M. Villa, Helv. Chim. Acta, 92 (2009) 2038-2051.

[47] G. Steinhauser, G. Giester, C. Wagner, N. Leopold, J.H. Sterba, B. Lendl, M. Bichler, Helv. Chim. Acta, 92 (2009) 1371-1384.

[48] G.-W. Yang, D.-Y. Chen, C. Zhai, X.-Y. Tang, Q.-Y. Li, F. Zhou, Z.-F. Miao, J.-N. Jin, H.-D. Ding, Inorg. Chem. Commun., 14 (2011) 913-915.

[49] Z.-R. Qu, Z. Xing, B.-Z. Wu, X.-Z. Li, G.-F. Han, Z. Anorg. Allg. Chem., 635 (2009) 39-42.

[50] W. Dong, J.M. Lin, D.Y. Wang, J. Guangzhou Uni. (Nat. Sci. Ed.), 8 (2009) 53.

[51] C.-Y. Ma, W.-B. Chen, J.M. Lin, S.-H. Guo, A.-J. Zhou, W. Dong, Chin. J. Inorg. Chem., 27 (2011) 1436.

[52] Y.X. Qiu, M. Yang, H. Yan, F.-X. Gao, Z.-J. Ouyang, W. Dong, Chin. J. Inorg. Chem., 29 (2013) 1072.

[53] Y. Liu, L. Gao, X. Lv, J. Liu, T. Hu, Inorg. Chem. Commun., 19 (2012) 15-18.

[54] X.-L. Chen, X.-G. Zhang, L.-J. Gao, H.-Y. Ma, Chin. J. Inorg. Chem., 32 (2016) 167.

[55] D. D'Alessio, S. Muzzioli, B.W. Skelton, S. Stagni, M. Massi, M.I. Ogden, Dalton Trans., 41 (2012) 47364739.

[56] D. D'Alessio, B.W. Skelton, A.N. Sobolev, A.M. Krause-Heuer, B.H. Fraser, M. Massi, M.I. Ogden, Eur. J. Inorg. Chem., 2016 (2016) 5366-5372.

[57] X.Q. Zhang, Q. Yu, H.D. Bian, S.P. Yan, D.Z. Liao, W. Gu, H. Liang, Aust. J. Chem., 61 (2008) $303-309$.

[58] D. Ding, M. Zhang, L. Li, Y. Fan, H. Hou, J. Coord. Chem., 62 (2009) 2675-2681.

[59] Q.-Y. Li, G.-W. Yang, X.-Y. Tang, Y.-S. Ma, W. Yao, F. Zhou, J. Chen, H. Zhou, Cryst. Growth Des., 10 (2010) 165-170.

[60] J.H. Zou, D.Y. Chen, G.W. Yang, Q.Y. Li, J. Yang, L. Shen, RSC Adv., 5 (2015) 27887-27890.

[61] J.H. Zou, D.L. Zhu, F.F. Li, F.S. Li, H. Wu, Q.Y. Li, G.W. Yang, P. Zhang, Y.X. Miao, J. Xie, Z. Anorg. Allg. Chem., 640 (2014) 2226-2231.

[62] J.H. Zou, J.N. Zhu, H.J. Cui, Z. Wang, D.L. Zhu, H. Tian, F.F. Zhang, J. Wang, Q.Y. Li, G.W. Yang, Aust. J. Chem., 68 (2015) 889-895.

[63] Y.M. Lu, J. Wang, J. Wu, K.K. Ding, Y.K. Li, L.L. Miao, Q.Y. Li, G.W. Yang, Inorg. Chim. Acta, 450 (2016) 395-401.

[64] Z.-F. Liu, M.-F. Wu, S.-H. Wang, F.-K. Zheng, G.-E. Wang, J. Chen, Y. Xiao, A.Q. Wu, G.-C. Guo, J.-S. Huang, J. Mater. Chem. C, 1 (2013) 4634.

[65] L.L. Wu, J.F. Zhao, H. Wang, J.Y. Wang, CrystEngComm, 18 (2016) 4268-4271.

[66] J. Jia, J.N. Xu, S.Y. Wang, P.C. Wang, L.J. Gao, M. Yu, Y. Fan, L. Wang, CrystEngComm, 17 (2015) 6030-6036.

[67] C. Knoll, D. Müller, G. Giester, J. Ofner, B. Lendl, P. Weinberger, G. Steinhauser, New J. Chem., 37 (2013) 3840.

[68] G.E. Kostakis, G. Abbas, C.E. Anson, A.K. Powell, CrystEngComm, 10 (2008) 1117.

[69] G.E. Kostakis, G. Abbas, C.E. Anson, A.K. Powell, CrystEngComm, 11 (2009) 82-86.

[70] G.E. Kostakis, K.C. Mondal, C.E. Anson, A.K. Powell, Polyhedron, 29 (2010) 24-29. 
[71] Y.-H. Tan, J.-B. Xiong, J. Huang, J.-X. Gao, Q. Xu, Y.-M. Yu, Y. Wang, B. Yang, Q. Shu, Y.-Z. Tang, Chin. J. Inorg. Chem., 30 (2014) 1621.

[72] F. He, M.L. Tong, X.L. Yu, X.M. Chen, Inorg. Chem., 44 (2005) 559-565.

[73] C. Zhai, M.Y. Guo, D. Xu, Z.Y. Yang, X.Q. Gu, Q.Y. Li, G.W. Yang, Inorg. Chem. Commun., 79 (2017) 5-7.

[74] X.N. Hao, B.H. Zheng, T.P. Hu, Chinese J Struc Chem, 35 (2016) 1186-1194.

[75] X.M. Zhang, P. Li, W. Gao, F. Liu, J.P. Liu, J. Solid State Chem., 244 (2016) 6-11.

[76] Y.B. Lu, X.M. Jiang, S.D. Zhu, Z.Y. Du, C.M. Liu, Y.R. Xie, L.X. Liu, Inorg. Chem., 55 (2016) 37383749.

[77] J. Wang, F.F. Zhang, B. Wei, Q. Wu, M.J. Cao, Y. Bai, G.W. Yang, Z. Anorg. Allg. Chem., 642 (2016) 169-173.

[78] L.L. Miao, M.Y. Guo, J. Wu, Y.M. Lu, Q. Wu, Y. Bai, Q.Y. Li, G.W. Yang, Inorg. Chim. Acta, 450 (2016) 176-181.

[79] Q. Wu, M.J. Cao, B. Wei, Y. Bai, H. Tian, J. Wang, Q. Liu, Q.Y. Li, G.W. Yang, Inorg. Chem. Commun., 62 (2015) 111-114.

[80] J.N. Zhu, Q. Liu, F.F. Zhang, L.Y. Zhao, H. Tian, B. Wei, Q.Y. Li, G.W. Yang, J.H. Zou, Z. Anorg. Allg. Chem., 641 (2015) 1881-1885.

[81] M.J. Cao, Y.K. Li, P.P. Sun, C.Y. Zhang, J. Wang, Q.Y. Li, G.W. Yang, Z. Anorg. Allg. Chem., 642 (2016) 1218-1221.

[82] L. Shen, Y.T. Min, X. Bai, J. Wang, Q. Wu, J. Yang, H.J. Chen, F. Geng, G.W. Yang, Q.Y. Li, Z. Anorg. Allg. Chem., 642 (2016) 1112-1119.

[83] M.-H. He, C. Ji, Z.-D. Shen, Q.-Y. Li, G.-W. Yang, W. Shen, Q.-G. Qiou, X.-F. Shen, J. Coord. Chem., 66 (2013) 1538-1548.

[84] J. Wang, J. Nie, C. Dai, J. Coord. Chem., 64 (2011) 1645-1653.

[85] W.B. Chen, Z.X. Li, X.W. Yu, M. Yang, Y.X. Qiu, W. Dong, Y.Q. Sun, Dalton Trans., 43 (2014) 90909097.

[86] W.B. Chen, Z.X. Li, Z.J. Ouyang, W.N. Lin, L. Yang, W. Dong, RSC Adv., 4 (2014) 61104-61113.

[87] L. Liang, G. Peng, G. Li, Y. Lan, A.K. Powell, H. Deng, Dalton Trans., 41 (2012) 5816-5823.

[88] L. Liang, G. Peng, L. Ma, L. Sun, H. Deng, H. Li, W. Li, Cryst. Growth Des., 12 (2012) 1151-1158.

[89] L. Liang, G. Li, L. Sun, G. Lan, L. Zhang, C. Yang, Y. Ma, H. Deng, Inorg. Chem. Commun., 20 (2012) 295-298.

[90] Y. Xiao, S.H. Wang, F.K. Zheng, M.F. Wu, J. Xu, Z.F. Liu, J. Chen, R. Li, G.C. Guo, CrystEngComm, 18 (2016) 721-727.

[91] C.-F. Qiao, Q. Wei, Z.-Q. Xia, C.-S. Zhou, S.-P. Chen, J. Therm. Anal. Calorim., 107 (2011) 527-533. 